\title{
The Parlement of the Thre Ages: some notes on the place of origin of one of its manuscripts
}

\author{
ISABEL MOSKOWICH-FANDIÑO \& ELENA ALFAYA
}

\section{Introduction}

The central goal of the present study is to explore the geographical origins of $T$, one of the manuscripts of the medieval alliterative poem The Parlement of the Thre Ages (British Museum, MS 31042). For this purpose we will make use of Offord's edition of the poem as well as of A Linguistic Atlas of Late Mediaeval English.

Following Gillièron's proposal (1918: 1-18) that every word has its own history and dialectal distribution in Middle English we will pay attention to written variations in this text and disregard pronunciation so as to achieve an exact localisation for them. To this end we will make use of the fit-technique. In particular, an effort has been made to demonstrate how this Atlas can be used as well as to show the way in which any medieval manuscript may be located in a particular place in England by means of this powerful tool.

A description and analysis of the corpus opens this study. It is followed by a detailed account of A Linguistic Atlas of Late Mediaeval English and the fit-technique. The next step towards achieving our goal is, perhaps, the most disclosing. The poem is analysed by means of the above mentioned fit-technique and then the place of origin not only of the scribe who copied the $T$ version of The Parlement of the Thre Ages but also that of the author are found out. Some theories about the areas from which the poem originally came will also be contrasted here.

\section{The Corpus}

\subsection{A Description}

The Parlement of the Thre Ages is a fifteenth century alliterative poem of which two old manuscripts are kept in the British Museum. One of them is a complete version whereas the other is lacking some verses. The former was assembled in the fifteenth century by Robert Thornton $(T)$. The second version of the poem is known as $W$ because it was Sir James Ware who fitted the parts of it together in the seventeenth century. An overview of the formal characteristics of both manuscripts may help identify the dates in which the scribes copied them.

The practice of the scribe of the Thornton MS corresponds to the usual one in the fifteenth century. For instance, he makes use of an Anglicana hand, he uses for capital and he does not differenciate between and. Besides, there is no punctuation and he uses certain marks as abbreviations. As for contractions the scribe usually writes $z u, w t$ and $z e$ instead of zou, with or ze and he writes a stroke over a vowel when he is omitting the second in a diphthong.

Concerning the Ware MS (henceforth, $W$ ) it is clearly a more recent version if we compare it to the Thornton MS (henceforth, $T$ ). Thus, $T$ has hym to fote whilst $W$ has to his fote where $T$ is definitely representative of a word order closer to the one seen in OE with the preposition "postposed" when accompanying personal pronouns.

There are more clues in our two manuscripts providing information about the theory that $T$ is older than $W$. Concerning phonology, for instance, $W$ has sought and $T$ has soughten. The dropping of final $/ \mathrm{n} / \mathrm{in}$ inflexional endings has not taken place in $T$ but it has in $W$. The 
weakening and levelling of /e/ to schwa in unstressed positions and silencing of schwa written $<$ e $>$ has not occurred either.

We also find vocalisations of consonants in $W$ that have not occurred in $T$ yet.

The same happens with by-fore in $T$ and before in $W$, since the prefix is reduced during the ME period. Again, $W$ has bylovid whilst $T$ has by-luffede ( $T$ does not graphically reflect voicing in this form).

The missing lines in $W$ seem to indicate that the scribe failed to notice them as well as the whole first part of the poem.

Many names that we can read in $T$ have been ruined in $W$. In $W$ most names are no longer in their original state. We are not able to identify them when reading because we do not have a clear awareness of them. Some others have appeared in $W$ as innovations not present in $T$.

Many examples could be mentioned to demonstrate that $W$ is almost unquestionably a more recent version and that it maintains fewer of the ancient constructions.

$W$ is thought to have been written from the end of the fifteenth century to the seventeenth century and this period is not studied in A Linguistic Atlas of Late Mediaeval English. So, since it is out of our scope it will be left aside. Instead, we will focus on $T$ that seems to have been written during the fifteenth century (Offord, 1967: xii).

\subsection{The Thornton MS}

Some of the most outstanding features of the poem as regards phonology and spelling are already indicated in M.Y. Offord's edition of the poem (1967: xvii-xxii). It could be useful to examine its morphology as well since this may be indicative of the geographical area where the work has its origin. We will add some new examples to those already proposed by the editor (1967: xxiii). Thus,

-Infinitive forms end in -e, -en, -yn, -Ø: happen (line 5), telle (line 103), bye (line 147), kythe (line 168), seruen (line 218), be-tyde (line 596).

-Present indicative forms end in -e, -Ø (1 sg.): hete (line 643), sett (line 269); -es, -ys, -is (2 and 3 sg.): gloes (line 188); and - en, -yn, -es, -is, -on, -e (Pl.): knelyn (line 229)

-Pronouns: The most notable forms are scho (fem.s.) and thay, thaire (pl.). Hir, hyr (refl.); they, thaym, pam, pay are also usual forms in $T$.

-Nouns may appear with historical final $-e$ as in hunte, bagge, gome.

-Adjectives (both weak and strong) may be found to have an -e ending as well: longe (line 28), sadde (line 333).

In addition to inflectional simplification, there is a wider use of prepositions in ME: $p e$ fete of the fourche ... (line 91) to express the relationship otherwise conveyed by the genitive in OE. As for determiners, we should take into account the fact that grammatical gender is going to be replaced in ME by natural gender. This phenomenon seems to have started earlier in northern dialects whereas in the south-eastern dialect area of medieval England (Kent), grammatical gender was retained until the end of this period, since this area in the south of the country is much more conservative. In The Parlement of the Thre Ages grammatical gender has been lost.

Adverbs show the suffixes -lik and -liche that belong to the north and the south part of England respectively as well as -ly that we have in PE and that first appeared in the East Midlands.

If we study the vocabulary used in this alliterative poem we will find out, as pointed out by Offord, that it is very rich and that there is a great deal of French and Scandinavian elements (normally found in the language between 1150 and 1400). According to Offord (1967: xxvi), there are in this poem nearly one hundred words which could have a Scandinavian origin. Some of these words may be typical of the place of origin of the author and copyist since they are not used in other parts in England. In his own words (Offord, 1967: xxviii): "Other Scandinavian borrowings, not distinctively N. but 
uncommon in ME, are: bole "tree-trunk", coloppe, crab(tre), dreghe adj., lythe, mukkede, taytte(ly)."

There are also some French loans in The Parlement of the Thre Ages and it is not surprising that they are related to those passages in which the poet refers to hunting, sport or where there appears a description of the clothes someone is wearing. Some of these words are (Offord, 1965: xxviii): noble (line 280), chaplet (line 118), troches (line 67), fawkons (line 222), dame (line 357).

The native element represents those words that are synonyms for "people" or "man": beryn(e) (line 110), douth (line 348), hathelle (line 111) and in those OE words that became antiquated in ME: brande (line 371), bewes (line 370) or axles (line 113).

According to Rolf Kaiser (1965: xxvii) local or dialectal words can also be found and consequently, he listed some belonging to the North area of the country. Likewise he also listed those that represent the South part of England, all of them of native origin. Thus, in The Parlement of the Thre Ages we can find words typically occurring only in the North area in Medieval England: bodworde (line 558), fatills (line 20), hopynge (line 164), threpe (line 268), whills (line 604) and so on.

The total number of lexical items used by the poet is exceptional precisely because of its variety as well as due to the way this vocabulary is combined together.

\section{Methodology}

Over the years the study of the morphology of a particular text was sufficient to adscribe it to a dialectal area in medieval England. This can now be done by means of a new technique devised by A. Mclntosh, M. L. Samuels and M. Benskin. This particular way of ascertaining the provenance area of a text is called fit-technique. A Linguistic Atlas of Late Mediaeval English is said to spare no effort to infer the exact point in England where the language of any manuscript between 1300 and 1500 comes from $^{1}$. In general, we can say that scholars started from perfectly localised pieces of writing (known as "anchor texts") so that they could fit others with quite a good safety margin. In Laing's (1991: 28) words "Anchor texts are those that can be associated more or less confidently with specific places on non-linguistic grounds. Most of the anchor texts used in $L A L M E$ are of a documentary type."

The more texts they fitted the easier it was fitting the rest. This is said to be the main feature and newness of the Atlas, being in the position of localising nearly any medieval text whose origin is not clear, starting from written language and not from the evolution of sounds. This process by which we can allocate unlocalised texts to a certain place is called the fit-technique. Unlocalised texts can be placed starting from those that are already localised by an increasing elimination of the areas to which the linguistic profile ${ }^{2}$ of the scribe does not belong, and so establish the limits of the area to which the written varieties we are analysing belong to.

The first task which may be undertaken is to narrow the probable area of origin of our text. Every time that a heading for a group of different forms considered as similar in their way of operating and in meaning - an item - is examined, a part of England will be rejected or omitted if our particular spellings of the items chosen cannot be found there.

Item by item the probable provenance area of our text is made smaller and reduced to that part of England where the different items of our questionnaire overlap. It is also evident that the more items we consider the more strongly connected the group of linguistic variants will be. That is the reason why maps of different kinds are absolutely essential and we cannot do without them.

The Dot Maps in the Atlas are a help to interpretation for they reflect how operational equivalents occur together. They tell us the sharing out of items all along the country. As McIntosh (1986: 297, vol. 1) puts it: "The maps are, in the first instance, an answer to the question "What is the distribution of form $\mathrm{x}$ ?"”. 
A second type of maps is Item Maps. A problem with them is that the placings of particular linguistic profiles (henceforth, LP) on item-maps may not occur in any human settlement which, at first sight, might suggest that our results are wrong. This type of map deals with LPs and our placing would probably correspond to the "peak" or centre of the dialectal area to which that particular LP belongs. This area covers a distance of less than about a five-mile radius where we could find the historical place of origin, and let us not forget that the dialects of closely neighbouring villages may be different.

Linguistic profiles are written lists of all the words used in a particular place ${ }^{3}$. Though each LP represents the language of one scribe, it is also a sample of the literary community the scribe comes from. As McIntosh states (1986: x) every LP presents the following information:

The source from which an LP is derived.

The hand that is represented by the attached LP.

The parts of the manuscript for which the scribe is responsible.

Codicological or any other information which could be useful in some way or another for dialectal inquiry.

The particular sample of the scribe's work that was analysed and studied before being incorporated into the LP.

The grid reference to file place at which file LP is entered on file maps.

Following the different sets of maps, the County Dictionary is the fourth part of this Atlas and an index to the Linguistic Profiles.

\section{An Interpretation}

Thus far we have been considering the Thornton MS and the Atlas separately. In this section we turn to consider the information we can obtain by using both of them together and bring to light the results of our research. Our data comprise seventy-two entries that are analysed following the fit-technique. Subsection 3.1. deals with previous studies about the provenance of $T ; 3.2$. centres around the scribe's attitudes regarding verse texts; 3.3 . focuses on the scribal-target dialect whereas 3.4. studies the authorial-source one.

\subsection{Previous studies on the provenance of $T$}

Dialectal studies had left aside many texts for a long time because it was extremely difficult to achieve an exact localisation for them. There are usually many manuscripts of a text and yet they are not written in the same way. A dialect could be considered as a group of linguistic constituents with their own distribution. Some of its forms may be limited to the dialect in question but many others will be also shared by the nearby dialectal areas.

There are two different sets of ideas that intend to explain the provenance of The Parlement of the Thre Ages. On the one hand, J. P. Oakden thinks that the T version of the poem was copied by someone who came from the North East Midlands though it would have been originally written in the North West. As Offord says (1967: xxv):

... Oakden ... would place them in the extreme NW, near the Ribble Valley. Parl. too, he thinks, was written in the NW, but the scribe was EN. Midl. It could indeed be suggested that the easterly features were traces of Robert Thornton's own dialect, since he probably came from Yorkshire, but there is no need to assume that the E. Midl. features are all scribal; ...

One of the reasons why Oakden places the poem in the North West is because it has lots 
of similarities with Morte Artur, The Wars of Alexander, St. Erkenwald Awntyrs and The Destruction of Troy which have been localised in the North West Midlands.

On the other hand, Offord tells us that M. S. Serjeantson (1967: xxv) considers that the original dialect of this poem would be that of Nottinghamshire (North Central Midlands). Offord himself disagrees with this viewpoint because he considers that Nottinghamshire is not a northerly enough county to explain the great deal of northern features that the poem contains. He also considers that Oakden is right in placing the poet's dialect not far away from the Ribble boundary. What Offord personally feels is that the poem could be originally North West Midlands, from the central or southern part of the West Riding of Yorkshire.

We cannot help realising that these conclusions are not precise enough to place either $T$ or $W$ but also the original text from which these other two come. These excluded texts that have been rendered from the original dialect to their own are also important because they are the major potential source of "authentic" dialect material that we have with reference to The Parlement of the Thre Ages.

Under these circumstances, our approach will not only focus on the lost original text but also on $T$, since it is assumed to be representative for the genuine dialect of scribes. Furthermore, we should remember now that nearly any Middle English text can be localised and it is not necessary for it to be the original first verse text by the author because when analysing it we can separate the two dialects (layers) or more. That is to say, a copied text can tell us a lot about the dialectal area of the copyist once it has been localised, but also about the author and source dialect. In fact, what we have tried to do with $T$ is to localise it by means of the fit-technique and try to discover the source and target dialects.

\subsection{The scribes' attitudes towards verse texts}

Middle English constitutes a stage in the history of language most highly characterised by a range of difference in written form. Dialects had already been spoken at all preceding ages and it is in the course of the late medieval period that written forms as the expression of small areas of the country are seen at their best. In fact, we could state that nearly any medieval item ${ }^{4}$ written before 1450 could doubtless be labelled "dialectal".

We may suppose that the usual way scribes behaved in relation to copying manuscripts in Medieval England was that of rendering texts into their own dialect. Benskin and Laing (1991) say that translation seems to have been the most common scribal reaction to an exemplar in the late Middle English period. In other words, such scribes used to read the manuscript they were handling while they translated its forms into the ones commonly used by them and characteristic of the place where they had been educated. In this sense, copies of these times could be considered to be a manifestation of the real and exact dialect of the translating scribe. Thus it is important to remark that this practice of translation or adaptation from one dialect into another is to be found as a result of an attitude different from ours. The role of the translator was different from what it is today: he had in a way, more freedom and could somehow behave as a creator, producing the text ... (Moskowich and Alfaya, 1998: 103).

The previous claim is true of all types of texts, including verse. It needs to be acknowledged that on the one hand scribes might keep the forms of the verse text they are copying or not. On the other hand, they used to make a fairly accurate copy of the alliterative usage, that is, they reproduced the authorial rhyme and alliterative spellings as they were in their texts. Thus, scribes maintained alliteration as they found it in their exemplars and consequently, copies at very many removes from the original may keep the authorial alliterative spelling. This was mainly due to the fact that translations that did not keep alliteration did not work because they brought about non-interesting rhymes and alliterations no longer attractive. So, the usual thing was that translating scribes 
reproduced the authorial spellings if they took place in an alliterative position whilst the rest of the items were reproduced in one of the three following practices (McIntosh et al., 1986):

1. literatim-copying

2. translation

3. something between the two poles

Some of these scribes made a completely accurate copy of the whole alliterative spelling whereas others duplicated only the alliterative consonant. Notwithstanding this, we should not expect scribes to keep just the alliterative usage and render the rest of the items into their genuine dialect since any of the above mentioned attitudes might be adopted. In addition to this, we can affirm that the fifteenth century is a period of changes as regards scribal behaviour because it represents a gradual change from rendering to copying ${ }^{5}$.

Alliterative uses are not recorded in LPs.

In general, rhyming and alliterative uses are not reported in the LPs. Scribes who, in course of copying, regularly translate the language of an exemplar into (presumably) their own familiar form of ME, commonly transmit rhyming and alliterative forms unaltered: were these forms likewise translated, then the organising principles of the verse would be variously disrupted. (McIntosh, 1986: xviii (vol. 2)).

It is generally admitted that those scribes who copied alliterative poems used to transmit these alliterative forms unaltered and therefore, we may admit within reason, that the use of a particular scribe was nearly the same as the author of the poem had had. As Benskin puts it (1986:17):

The principle here is that, in order to preserve the alliterative fabric of the verse, a translating scribe reproduces the authorial forms whenever they occur in alliterative position... We should note additionally that the whole of the alliterative spelling, not just the alliterative consonant, is in principle to be excluded from the scribal dialect.

The remarkable thing here is not that some scribes should fail to separate the sourceauthorial dialect from the target-scribal one, but rather that so many copyists should obtain a remarkable high degree of consistency.

Translating scribes used to follow their exemplar in such a way as to suppress some of their own habitual and dialectal forms in order to maintain alliteration usage but they made use of their own language in the rest of the manuscript. Except for the occasional inconsistent scribe, we may assume this is the way scribes behaved when they reproduced poetry.

From this follow two general observations on the behaviour of scribes in late Medieval England as to alliterative poetry:

a. The source language is generally preserved in the alliterative use.

b. The target language is the one used in the rest of the poem.

In principle, therefore, at least two medieval dialects are to be assignable to any alliterative poem copied in the late Middle English period: one belonging to the author's source language and another belonging to the translating scribe.

In the case of a "contaminating" scribe, he might lead the dialectologist in the wrong direction since he might imitate the use of the exemplar for (say) half the items and exclude some others. A scribe who treats language inconsistently might cause difficulties 
for the dialectologist. However, and as previously suggested, this is not the case of a contaminating copyist of an alliterative poem, since contaminated rhymes and alliterations would be ruined and consequently we would omit them when trying to locate the geographical origin of the author of the poem. Of course, it would be just the opposite if we were trying to locate the geographical origin of the copyist. In the particular case of $T$, Thornton is considered to have imitated his exemplars faithfully, in spite of the different textual states in which he got his sources (Stern, 1976). It seems also helpful to comment on our scribe's conservationism and tendency to self-correct (Lawton, 1982) which could lead us to somewhere halfway between his real place of origin and that of the previous layer of copying through which the text might have passed.

In principle a more or less consistently translated alliterative poem in which the scribes make a good use of both target and source languages may be localised on a dialect map. It is here, in such alliterative poems, that we are likely to learn most. As pointed out before, one cannot always be sure of the exact limits of the consistency of a scribe. But the most important features for the source and target dialects may be identifiable and it is on this basis that it is possible to find out the origins of the author and copyist of a verse text.

\subsection{The copyist-target language}

We are now ready to consider the problem of more immediate concern to us here, namely the question of the provenance of $T$. We are going to focus on where the copyist of $T-$ namely Robert Thornton ${ }^{6}$ of East Newton, North Yorkshire - learnt to write.

Due to the facts commented in section 3.2, alliterative forms have not been included in our analysis of the copyist-target language and such important words as good, hundred, fellow, cast or know have been disregarded. Our scribe had a tendency to copy rather than to translate. However, we should not tend to have an impression of Thornton as a copyist since it is not clear to what extent this was his behaviour as a scribe. As Mclntosh states (1962: 231):

Robert Thornton was not by habit a scribe who transformed or "translated" exemplars so thoroughly as to obliterate all those characteristics in them which were alien to his own.

In the light of this declaration, it would also be necessary to take for granted that many of the dialect features we are going to analyse may belong to a previous copyist, which may lead us to a distinct layer of scribal copying. As a consequence of this, the geographical localisation we get (the place where Thornton learnt to write) should be contrasted with a new analysis of other works he copied. But this is material for future studies. The question is that the same scribe's profile can be considerably different in other manuscripts, so all of them should be analysed to obtain a more complete picture of our scribe's real linguistic profile.

In order to analyse the copyist language in $T$ it may be useful to situate the poem at a precise position in England with the help of the fit-technique. The process that has been followed to find it out revolves around maps and questionnaires and is the one that comes next.

We began by devising a questionnaire valid for the whole country since we do not know the origins of $T$. The items are spelt differently depending on the dialectal area we choose and, therefore, words written nearly the same all over the country have been excluded. Table 1 below shows two columns: (i) the questionnaire reference in which fourteen items have been included and, (ii) the different ways in which these items are actually written by the copyist of $T$ and one of the lines where it occurs in the edition by Offord. This is what has been suggested so far:

Once the questionnaire had been completed its corresponding dot maps were drawn to 
Table 1. Questionnaire valid for the whole country

\begin{tabular}{ll}
\hline Questionnaire reference & Equivalent forms in Thornton MS \\
\hline TOGETHER adv. & to-gedir (1. 434), to-gedire (1. 83), to-gedirs (1. 600) \\
THESE adj. or pron. (pl.) & theis (1. 610), thes (1. 220), this (1. 182), thies (1. 109) \\
SHALL. SHOULD aux. & sall (1. 168), schalte (1. 257), schall (1. 648), scholde (1. 82) \\
FIRE n. & fyre (1. 593) \\
EACH adj. & iche (1. 15) \\
SHE pron. & scho (1. 540) \\
THEM accus. & thaym (1. 105) \\
IS vb. & es $(1.177)$ \\
STRENGTH & strenghte (1. 532) \\
SEE pt. s. & seghe $(1.509)$ \\
\hline
\end{tabular}

represent the dialectal distribution of the previously selected items. Regions where this form is never used by any scribe have been represented by means of circled areas with red lines crossing (hereafter, eclipsed areas). From map to map we have bigger and bigger eclipsed areas which stand for those regions where we could not find the forms that the scribe of the Thornton MS wrote as a custom. Following the fit-technique we got to a very delimited area which could be probably set in one of the following counties: Yorkshire, West Riding, Nottinghamshire, Derbyshire or even Lincolnshire or Yorkshire, East Riding.

It is likely that the place where Robert Thornton learnt to write is one of the previously said north-Midlands counties so a second questionnaire corresponding to Northern England was also devised.

This northern questionnaire (Table 2) is composed of nine items as well as of nine dot maps that represent them and the process is similar to the one used for the whole country.

The data from this questionnaire and its corresponding dot maps suggest that the place of origin of the language of the Thornton MS. belongs to a county situated in the centre of the country. Far better, a place in the north-east, next to the Gulf of Wash and possibly, in the area round the river Trent valley. By far, and given the arguments provided by dot maps, it seems clear that we have abundant evidence to affirm that the county we are looking for is Yorkshire, West Riding, Nottinghamshire, Derbyshire or even the east part of Lincolnshire, the northern part of Leicestershire or Yorkshire, East Riding.

The obvious question now is what evidence is there in support of the selection of one of these counties. Item maps have been totally decisive and conclusive to reject some of these counties and to get to the exact place where our scribe learnt to write and hence, they have made it certain that we can achieve a particular result by using them. Item maps just represent the distribution of a single word county by county, each point embodying a different linguistic profile. Using these item maps we will not see where $\mathrm{OE} / \mathrm{a} / \mathrm{changes}$

Table 2. Questionnaire for the northern area

\begin{tabular}{ll}
\hline Questionnaire reference & Equivalent forms in T \\
\hline CAN vb & kane (1. 425) \\
EARTH n & erthe (1. 18) \\
ABOUT adv & abowte (1. 46), aboute (1. 93) \\
DOWN adv & doun (1. 52) \\
FIGHT vb & fighte (1. 301) \\
OTHER pron & oper (line 15) \\
EYE(S) n & eghne (1.549) \\
CAST pt & keste (1. 80) \\
THIRD pron & thirde (1. 472) \\
\hline
\end{tabular}


Table 3. Item Maps

\begin{tabular}{|c|c|}
\hline Items mapped & Forms in $\mathrm{T}$ \\
\hline THESE & theis (1. 610), thes (1. 220), this (1. 182), thies (1. 173) \\
\hline HER & hir (1. 20), hyr (1. 608) \\
\hline THEM & thaym (1. 234), pam (1. 381) \\
\hline THEIR & thaire (1. 107), theire (1. 16), paire (1. 303) \\
\hline $\mathrm{EACH}$ & iche $(1.15)$ \\
\hline NOT & noghte (1. 288) \\
\hline SHALL sg. & schall(e) (1. 258), sall (1. 168), schalte (1. 257) \\
\hline STRENGTH & strenghte (1. 532) \\
\hline THOUGH & poghe (1. 243) \\
\hline
\end{tabular}

and where it does not, but we will see where medieval scribes used to write $<$ a $>$ and where they used to write $<0>$ (for instance in stan). Many words have been considered in detail in order to exclude those that are representative of all these counties. Only one particular area of one of these counties may eventually be selected so we chose twenty-one key items sharing the characteristic that they always eclipse some of the other counties or some Linguistic Profiles. Let us bear in mind that every LP is a sample from a literary community and as Mclntosh states (1986: ix):

In principle, each LP represents the language of one and only one scribe. In relatively few cases have the products of two or more hands knowingly been incorporated in a single LP (...).

The LPs are grouped in sections, according to the county or other specified region to which their language belongs. Within each section the LPs are ordered by key-number.

Table 3 shows nine of the 21 key-items selected to draw item maps. There are two columns: the first one symbolises the items mapped whereas the second one tells us what particular forms of the item can be found in our manuscript.

Having used these nine items we could easily see that Lincolnshire, Leicestershire and Yorkshire East Riding are not the counties where $T$ comes from since the items mapped excluded them. Yorkshire, West Riding was an accurate candidate and neither Nottinghamshire nor Derbyshire could hitherto be excluded. It can be established that the forms used of such common items as THEM, HER, EACH, NOT, SHALL and THESE used in $T$ appear just in Yorkshire, West Riding, Nottinghamshire and Derbyshire. We may also confirm that the forms of THEIR and STRENGTH used in $T$ cannot be found anywhere in Derbyshire and however, they are found in Yorkshire, West Riding and in Nottinghamshire, just in their borderline. As for the form of THOUGH -poghe- it is not used in Nottinghamshire. It is rarely used in Derbyshire and with a variant in Yorkshire, West Riding and in its border with Nottinghamshire (LP 217).

However, adjacent LPs are empty. This is to say there is not any alternative form. Concerning schall(e), sall, schalte, thym and pam, they just appear in Yorkshire, West Riding. We can also see two of these forms in the northernmost part of Derbyshire, next to the border with Yorkshire, West Riding. It seems that these nine items lead us to the southeast part of Yorkshire, West Riding and to its border with Nottinghamshire and Derbyshire.

Table 4 shows the other 12 key-items and their forms in the text.

Considering these new items in detail (left column) and the equivalent forms that $T$ shows (right column) we can infer that most of them appear in the LPs 479 and 591 or in other adjacent to them. Hence, the forms of the item WHERE (where and whare) are found in the LPs 479 and 591 though they are also found in some adjacent LPs $(234,175,473$ and others). The same happens with the items THROUGH, SHE and WILL. Whilst the form 
Table 4. Item Maps

\begin{tabular}{ll}
\hline Items mapped & Forms in $T$ \\
\hline WORLD & werlde $(1.149)$, worlde $(1.332)$ \\
IF & if $(1.168)$ \\
ARE & are $(1.283)$ \\
WHERE & w $($ here $(1.185)$, whare $(1.626)$ \\
MUCH & myche $(1.276)$ \\
THEY & thay $(1.367)$, pay $(1.222)$, they $(1.215)$ \\
THROUGH & thurg $(e)(1.91)$, thorowe $(1.238)$ \\
SHE & scho $(1.540)$ \\
SHALL pl. & schall $(1.648)$ \\
AFTER & aftir $(e)(1.277)$, aftyr $(1.226)$ \\
WILL pl. & will $(1.267)$ \\
WHILE & while $(1.270)$ \\
\hline
\end{tabular}

sall is mostly found in LP 479, the other form used schall is only found in LP 591 and they are next to each other. If we pay attention to WORLD, IF, ARE and to the conjunction WHILE, we can see that all their forms in $T$ appear in LPs 479 and 591. Schall is the only form in $T$ that we can find of shall (pl.). It is only found in LPS91. The scribe of $T$ uses just a form of the word MUCH (myche) and if we observe the maps, we can see that it is used in LP 169 to the south of LPs 479 and 591.

Two of the items mapped do not appear in LPs 479 and 591, namely, THEY and MUCH. Thay, pay, they and myche appear in LPs in the borderline with Yorkshire, West Riding whilst we find a similar form in LPs 479 and 591. Though these particular forms are not used in the LPs in question, we find them within a small radius, in LPs 217, 1102 and 169. This seems to demonstrate that our scribe and the scribes of LPs 479 and 591 are not the same person, but the three of them share quite a similar linguistic profile, in fact.

Thus, it seems that there is no point in placing $T$ in LP 479 or 591 with a blind faith but we can safely say that our scribe's Linguistic Profile can approximately be found within a five-mile radius from these LPs. The "peak" lies in the middle of the area to which the language represented by LPs 479 and 591 may belong. There are some villages that could be chosen as the historical place of origin of the language of our text. Besides, we should also take into account that we are not dealing with an original text but with a possibly fairly accurate copy, so we are bound to find features that do not form part of the scribe's own language but that are remnant forms from the original text or from previous copies. As Thompson (1987:4) puts it:

... the items in Thornton's collection have been variously contaminated in the course of their transmission. What is not so clear is the extent to which Thornton can be held personally responsible for some of that contamination, and in particular for some of the more intriguing changes that have taken place in the pre-history of these texts.

While dealing with copies we will have the problem of linguistic integrity. Consequently, it might be possible that the place where Thornton was educated was beyond the "peak". Nevertheless, the linguistic character of the other LPs adjacent to LPs 479 and 591, fix the place of provenance of the Thornton MS within a very small area and we cannot help realising that the alternative is no linguistic profile at all. Apart from this, we can also affirm that scribes travelled and their way of writing travelled with them. That could account for the presence of features from LPs 234 and 240.

To sum up, evaluation demonstrates that at least this time, language is not a fixity and that it is worth examining it, as it hides much information. We are likely to benefit from glancing at several LPs to find the local origin of our scribe. But we must also say that the 
LP for which our manuscript is truly representative is somewhere between/around LP 479 and LP 591 and that the point in which it stands is somehow uneven, with the result that our "peak" is not at the centre of its domain. Some miles between the above-mentioned LPs would be a better choice. But since it makes no real difference, we consider that the result that we have achieved is more than enough since the area over which LPs 479 and 591 have some influence is very delimited and totally reliable.

\subsection{The authorial-source dialect}

In alliterative verse like that of the Thornton manuscript of The Parlement of the Thre Ages the source and target dialects alternate constantly. Our nearly literatim-translating copyist rendered parts of it into his own dialect but he also kept the authorial usage as regards alliteration. This separation between the source and target dialects seems to be basic to achieve an accurate localisation.

Of course, it would be necessary but too long for this paper to know how far the copyist of $T$ fails to preserve the appropriate separations of authorial and scribal usages. We will take for granted that our copyist may occasionally include his own dialectal usage to the ruin of alliteration. Notwithstanding this, the localisation of the original text will not be influenced by such intrusion.

The following step in our study is, then, to separate both layers and deal with the source one in this section. In other words, we will just analyse alliterative usage, leaving the rest of the items aside to focus on the author of the poem and his use of language. The analysis of the authorial alliterative usage of $T$ may lead us to the place where the author of the Parlement of the Thre Ages learnt to write. Offord considers that the original dialect of the poem would be North West Midlands (1967: xxv-i):

... there can be no certainty as to the original dialect of the poem, but NW. Midl. is perhaps the most likely. The poet's dialect could have been that of the central or southern part of the West Riding of Yorkshire, but at this distance of time it is impossible to localize it exactly.

Thus far, we have been considering the limits between the exemplar's source and target languages. Once this has been established, we will try to locate the origins of $T$ by means of the analysis of the alliterative usage and the fit-technique. As Benskin puts it (1986: 7):

There is in fact a way that we can utilise more manuscripts than those which have been localised on non-linguistic grounds; the literary manuscripts can be incorporated into the matrix created by mapping of the anchor texts. This process we call the fittechnique.

Thus, and as previously done, we shall begin by devising a questionnaire valid for the whole country. There are two columns: (i) the questionnaire reference and, (ii) the different ways in which these items are written in $T$. Table 5. illustrates what has been suggested so far:

Once this questionnaire had been completed its corresponding dot maps representing their dialectal allocation were drawn. Such maps are, in the first place, a representation of the sharing out of the forms from the questionnaire. We should now remember that there are areas where some of these forms are never used by any scribe (eclipsed areas). In our particular case we get that the author of the poem copied by Thornton could probably be from central-south Yorkshire North Riding, south Yorkshire East Riding, Yorkshire West Riding, north-west Lincolnshire, extreme north and south of Derbyshire and Nottinghamshire, north Staffordshire and Cheshire, north-central Lancashire and Westmoreland.

Since all these places are in the north-midlands, we devise another questionnaire valid 
Table 5. Questionnaire valid for the whole country

\begin{tabular}{ll}
\hline Questionnaire reference & Equivalent forms in T \\
\hline BOTH adj. and pron. & $\begin{array}{l}\text { bothe (1. 55) } \\
\text { GOOD adj. and } \mathrm{n}\end{array}$ \\
\hline
\end{tabular}

for the north of the country so that we may arrive at a much more accurate region where we will be able to place the provenance area of the author of $T$.

From these data and given the arguments provided by dot maps, we can state the author of the poem copied by Thornton was from the central part of Yorkshire West Riding and in this way we would confirm one of the possible provenance areas suggested by Offord when the fit-technique was still a promising beginning.

\section{Conclusions}

All along this research paper we have been trying to emphasise that A Linguistic Atlas of Late Mediaeval English is useful, important and serious enough to make it worth studying. Previous dialectal studies of unlocalised manuscripts highlighted the need of introducing changes and new ideas finally provided by $L A L M E$. Not only does it bring forward the newness and priority of the written language but it also demonstrates the validity of the fittechnique.

After having applied the methodology of the fit-technique proposed by Mclntosh, Samuels and Benskin, we have been able to draw the following conclusions:

First, Serjeantson thinks that The Parlement of the Thre Ages represents the dialect of Nottinghamshire whilst Oakden places it next to the Ribble boundary. We agree with both of them to some extent since $T$ has proved to have been written within a small radius of LPs 479 and 591. These LPs are some miles to the north of Nottinghamshire and some miles to the south of the Ribble valley (south-east of Yorkshire, West Riding).

Second, our curiosity is satisfied with regard to the localisation of the written variety of $T$ and to the place where the author of the poem learnt to write. The first one has proved to be at the southernmost part of Yorkshire, West Riding. LPs 479 and 591 represent two unique ways of writing in the whole country and share most of their features with the Thornton MS. This scribe's language also shares some features with the bordering LPs 234 and 240, neighbouring spots placed in the same county. Regarding the author of this alliterative poem, it seems that his origins would be in the central part of Yorkshire, West Riding. Both of them being such close areas we could think of it as a matter of chance but there is also a possibility of contamination or of a scribal behaviour different to the generally admitted during the Middle Ages. Bearing this possibility in mind as a hypothesis, it would be interesting to know if it agrees or not with any further suggestions that are made.

Third, poetry is characterised by diversity of written forms sharing at least two layers of

Table 6. Questionnaire valid for the northern area

\begin{tabular}{ll}
\hline Questionnaire reference & Equivalent forms in T \\
\hline DAY n. & daye (1. 16) \\
MADE pret. & garte (1. 561) \\
FELLOW n. & felowe (1. 183) \\
CAST pret. & casten (1.212) \\
HEAVEN n. & heuen (1. 215) \\
\hline
\end{tabular}


copying when consistently translated if we are dealing with a copy and just one layer if we have an original exemplar. Scribes used to reproduce the alliterative and rhyming uses just as they found them. However, they usually rendered the rest of the poem into their own dialect. Thus, we should consider the distance between the exemplar and target dialects when handling medieval verse texts since such separation might be essential in the search for the place of origin of the author of the poem.

Departamento de Filoloxía Inglesa

Universidade da Coruña

E-15071 A Coruña

Spain

\section{NOTES}

1 The area covered by the Atlas is that of England, some parts of Wales and southern Scotland from 1350 to 1450. This span of time is not kept strictly since for some places of southern England the evidence from very valuable fourteenth century texts was included and therefore the period covered in this area stretches from 1325 to 1425 whilst the period 1350- 1450 is relevant for the north of England.

2 A Linguistic Profile is a discriminating index of the variants of the dialect in question. See vol. 1 of the Atlas for further details.

3 They are a set of variants that normally occur together and are, thus, attributed to one hypothetical single scribe.

4 The term item is here a heading for the group of the different forms of a word that are considered to have the same use and function and may, hence, distinguish dialectal usages.

5 The introduction of the first printing press in England in the fifteenth century gradually leads to the first standardisation in printing in the second half of the sixteenth century.

6 For a fuller account of the scribe see Stern (1976).

\section{REFERENCES}

Benskin, M. \& Riddy.F. eds. 1991. Regionalism in Late Medieval Manuscripts and Texts: Essays celebrating the Publication of A Linguistic Atlas of Late Medieval English. Cambridge: DS Brewer.

Davies, N. \& Wrenn, C.L. 1962. English and Medieval Studies Presented to J. R. R. Tolkien. London.

Davis, L.M. 1993. English Dialectology: An Introduction. Alabama: The University of Alabama Press.

Duncan, T.G. ed. 1995. Medieval English Lyrics 1200-1400. London: Penguin.

Gasiorowski, P. 1997. The Phonology of Old English Stress and Metrical Structure. Frankfurt am Main: Peter Lang.

Gillièron, J. 1918. Généalogie des Mots qui Désignent L’Abeille. Paris: Édouard Champion.

Laing, M. 1991. “Anchor Texts and Literary Manuscripts in Early Middle English”. In Benskin, M. \& Riddy, F. eds.

Lawton, D. ed. 1982. Middle English Alliterative Poetry and Its Literary Background. Cambridge.

Lester, G.A. 1996. The Language of Old and Middle English Poetry. London: Macmillan Press.

Mclntosh, A. 1993. "The Textual Transmission of the Alliterative Morte Arthure", in Davies, N. and Wrenn, C.L. eds. 231-240.

Mclntosh, A., Samuels and M. Benskin. 1986. A Linguistic Atlas of Late Mediaeval English. 4 vols. Aberdeen: Aberdeen University Press.

Mogg, R. \& C.B. McCully. 1989. Metrical Phonologv: a Coursebook. Cambridge: CUP.

Moskowich, I. \& Alfaya, E. 1998. "Translation in Middle English: A Problem of Scripts and Scribes". In Soto, L. \& Crespo, B. eds. Insights into Translation. A Coruña: Universidade da Coruña (101-111).

Offord, M.Y. 1967. The Parlement of the Thre Ages. Oxford: OUP.

Russom, G. 1987. Old English Meter and Linguistic Theory. Cambridge: CUP.

Stanley, E.G. 1978. "Review of the Thornton Manuscript", Notes and Queries, 223 (165-168).

Stern, K. 1976. "The London “Thornton” Miscellany”, Scriptorium, 30 (1976), 26-37.

Thompson, J.J. 1987. Robert Thornton and the London Thornton Manuscript. Cambridge: DS Brewer.

Wakelin, M.F. 1991. English Dialects. An Introduction. London: The Athlone Press. 